\title{
Retinal Ganglion Cells Survive and Maintain Normal Dendritic Morphology in a Mouse Model of Inherited Photoreceptor Degeneration
}

\author{
Francesca Mazzoni, ${ }^{1}$ Elena Novelli, ${ }^{2}$ and Enrica Strettoi ${ }^{1}$ \\ ${ }^{1}$ Istituto di Neuroscienze Consiglio Nazionale delle Ricerche, 56100 Pisa, Italy, and ${ }^{2}$ Fondazione G. B. Bietti per l'Oftalmologia, Instituto di Ricovero e Cura a \\ Carattere Scientifico, 00198 Rome, Italy
}

\begin{abstract}
Retinitis pigmentosa (RP), a family of inherited disorders characterized by progressive photoreceptor death, is a leading cause of blindness with no available cure. Despite the genetic heterogeneity underlying the disease, recent data on animal models show that the degeneration of photoreceptors triggers stereotyped remodeling among their postsynaptic partners. In particular, bipolar and horizontal cells might undergo dendritic atrophy and secondary death. The aim of this study was to investigate whether or not concomitant changes also occur in retinal ganglion cells (RGCs), the only retinal projection neurons to the brain and the proposed substrate for various therapeutic approaches for RP. We assessed the retention of morphology, overall architecture, and survival of RGCs in a mouse model of RP at various stages of the disease. To study the morphology of single RGCs, we generated a new mouse line by crossing Thyl-GFP-M mice (Feng et al., 2000), which express GFP (green fluorescent protein) in a small number of heterogeneous RGCs types, and rd10 mutants, a model of autosomal recessive RP, which exhibit a typical rod-cone degeneration (Chang et al., 2002). We show remarkable preservation of RGC structure, survival, and projections to higher visual centers in the time span from 3 to 9 months of life, well beyond the death of photoreceptors. Thus, unlike second-order neurons, RGCs appear as a considerably stable population of cells, potentially constituting a favorable substrate for restoring vision in RP individuals by means of electronic prostheses or direct expression of photosensitive proteins.
\end{abstract}

Key words: photoreceptor; mutant; phosphodiesterase; blindness; retinal ganglion cell; THY-1; GFP; survival; dendritic arborization

\section{Introduction}

Many common causes of blindness involve the death of retinal photoreceptors: in retinitis pigmentosa $(\mathrm{RP})$, mutations, typically in photoreceptor-specific genes, lead to progressive degeneration of rods and cones and gradual loss of all useful sight. A strategy for improving vision in RP is the development of prostheses based on retinal implants designed to electrically stimulate deep retinal layers, thereby taking over the function of lost photoreceptors (Zrenner, 2002; Rizzo et al., 2003; Loewenstein et al., 2004). Both subretinal and epiretinal electronic prostheses have the capability to stimulate retinal ganglion cells (RGCs) directly (Jensen et al., 2005; Jensen and Rizzo, 2006). Recently, a newer strategy has led to recovery of some visual function in animal models of RP by transgenic expression of photosensitive molecules directly in bipolar and RGCs (Bi et al., 2006; Lagali et al.,

\footnotetext{
Received 0ct. 15, 2008; revised Nov. 10, 2008; accepted Nov. 14, 2008.

This work was supported by the Italian Consiglio Nazionale delle Ricerche and by National Eye Institute Grant R01-12654. We are indebted to Shegang He for helpful suggestions on ganglion cell classification, to Richard $\mathrm{H}$. Masland for the generous gift of homozygous Thy1/GFP-M mice, to MariaCristina Cenni for helpful comments on this manuscript, and to Giulio Cesare Cappagli for excellent technical support. E.S. dedicates this paper to the memory of Ramon F. Dacheux, unforgettable retinal neuroscientist and mentor.

Correspondence should be addressed to Enrica Strettoi, Istituto di Neuroscienze Consiglio Nazionale delle

Ricerche, Via Giuseppe Moruzzi 1, 56100 Pisa, Italy. E-mail: enrica.strettoi@in.cnr.it.

D0I:10.1523/JNEUROSCI.4968-08.2008

Copyright $\odot 2008$ Society for Neuroscience $\quad 0270-6474 / 08 / 2814282-11 \$ 15.00 / 0$
}

2008; Lin et al., 2008). These strategies equally depend on the viability and survival of inner retinal cells after photoreceptor death.

In both humans and animal models of RP, the inner retina remodels on photoreceptor loss, undergoing regressive changes and secondary degeneration (Milam et al., 1998; Strettoi and Pignatelli, 2000; Strettoi et al., 2002, 2003; Jones et al., 2003; Marc et al., 2003; Cuenca et al., 2004; Jones and Marc, 2005; Gargini et al., 2007). The time course and sequence of events affecting bipolar, horizontal cells and retinal glia have been studied in some detail; however, effects on RGCs, the only retinal exit to the brain, are poorly understood, and few studies are available at the single-cell level. Estimates of RGC survival in animal models have led to somewhat contradictory results, whereas interpretation of human RP data are still difficult (Grafstein et al., 1972; Eisenfeld et al., 1984; Stone et al., 1992; Santos et al., 1997; Walia and Fishman, 2008). Functional studies have shown that RGCs might retain glutamate excitability even in the presence of alterations in input neurons implicating loss of glutamate-coupled depolarization mechanisms in cone bipolar cells (Marc et al., 2007). In a classical paradigm of RP, the rd1 mutant mouse, RGCs exhibit paroxysmal electrical activity after photoreceptor death (Stasheff, 2008). The aberrant activity seems generated by abnormal synaptic input, because the intrinsic membrane and firing properties of 
at least some types of RGCs appear preserved (Margolis et al., 2008).

Here, we report a longitudinal study of RGC structure and survival in the C57BL/6J-Pde6brd10/J mouse, commonly known as rd10 mutant, which carries a nonsense mutation of the $\beta$-subunit of the rod-specific phosphodiesterase gene (Chang et al., 2002). Humans with similar mutations display autosomalrecessive $\mathrm{RP}$, and this mouse can be considered a faithful model of the typical form of the disease (McLaughlin et al., 1993).

Using a single-cell approach, we show that all types of RGCs studied retain their dendritic architecture and overall viability, even after complete photoreceptor degeneration and regressive remodeling of the second-order neurons of the retina.

\section{Materials and Methods}

Animals. Experimental procedures were in accordance with institutional guidelines and with the Association for Research in Vision and Ophthalmology statement for the use of animals in research. All mice were kept in a local facility with water and food ad libitum, in a $12 \mathrm{~h}$ light/dark cycle, with illumination levels $<60$ lux.

C57BL/6J-Pde6brd10/J mutants (from here on, rd10 mice) and C57BL/6J wild-type controls (wt) were obtained from the The Jackson Laboratory. Mice of the B6.Cg-Tg(Thy1-GFP-M)JRS/RHM strain were a kind gift from R. H. Masland (Harvard Medical School, Boston, MA) and were homozygous for the Thyl-GFP allele. These were derived by breeding from the B6.Cg-Tg(thy1-YFP)/J strain originally devised by J. R. Sanes (Feng et al., 2000) and will be referred to as Thyl-GFP-M from here on. In these homozygous animals (Thyl-GFP/Thyl-GFP), a small number of RGCs (50-70 cells/retina) strongly express green fluorescent protein (GFP).

A total of 75 mice was used for this study. Transgenic mice of the Thy1-GFP-M strain, aged 3-9 months, were used as a set of founders. A new line of mice, Pde6brd10/rd10/Tg(Thy1-GFP-M)Jrs, from here on named rd10/Thy1-GFP-M, was obtained by crossing rd10 with Thy1GFP-M mice. Thy1-GFP-M mice were first crossed with homozygous $\mathrm{rd} 10 / \mathrm{rd} 10$ animals. Individuals obtained from the first generation $\left(\mathrm{F}_{1}\right)$ were backcrossed with $\mathrm{rd} 10 / \mathrm{rd} 10$ animals obtaining the $\mathrm{F}_{2}$. Genotyping was performed by PCR on tail-extracted DNA of $\mathrm{F}_{2}$ individuals to identify Thy1-GFP-positive animals. The following primers were used: ThylGFP forward (F) (AAGTTCATCTGCACCACCG) and Thy2-GFP reverse (R) (TCCTTGAAGAAGATGGTGCG), following a protocol recommended by The Jackson Laboratory. The PCR amplification of the corresponding $173 \mathrm{bp}$ fragment was performed in 35 cycles by denaturation at $94^{\circ} \mathrm{C}$ for $1.5 \mathrm{~min}$; annealing at 94,61 , and $72^{\circ} \mathrm{C}$, respectively, for $30 \mathrm{~s}, 1 \mathrm{~min}$, and $1 \mathrm{~min}$; and elongation at $72^{\circ} \mathrm{C}$ for $2 \mathrm{~min}$.

To identify mice homozygous for the rd10 mutation among Thy1GFP-M-positive individuals, a second PCR was performed. In this case, the primers were as follows: RD10 F (CTTTCTATTCTCTGTCAGCAAAGC) and RD10 R (CATGAGTAGGGTAAACATGGTCTG).

The corresponding PCR amplification was performed in 30 cycles by denaturation at $94^{\circ} \mathrm{C}$ for $3 \mathrm{~min}$; annealing at 94,60 , and $72^{\circ} \mathrm{C}$, respectively, for $1 \mathrm{~min}, 30 \mathrm{~s}$, and $1 \mathrm{~min}$, and elongation at $72^{\circ} \mathrm{C}$ for $7 \mathrm{~min}$. The product obtained was purified and digested with the enzyme $\mathrm{HhaI}$ (New England Biolabs), whose restriction site is not included in the rd10 mutant DNA. The recognized sequence is as follows: $5^{\prime}-\ldots$ G/CGC. . . - $3^{\prime}$ and $3^{\prime}$-. . . CGC/G. . . -5' (Chang et al., 2007). After $2 \mathrm{~h}$ incubation in the enzyme at $37^{\circ} \mathrm{C}$, the digested DNA was run on a Metaphor agarose (Cambrex) for separation of short DNA fragments. The homozygous rd10 mutation is revealed by the presence of a single band having a size of 97 bp.

GFP immunocytochemistry. rd10/Thy1-GFP-M mice, aged 3, 7, and 9 months, and Thy1-GFP, control mice, aged 8-9 months, were anesthetized with intraperitoneal injections of Avertin $(0.1 \mathrm{ml} / 5 \mathrm{~g})$ and killed with an overdose of anesthetic on eye removal. Eyes were quickly enucleated, a reference on the dorsal pole was taken with a lab marker, and a small cut was made at the corneal margin before immersion in fixative [4\% paraformaldehyde (PFA) in $0.1 \mathrm{M}$ phosphate buffer ( $\mathrm{PB}), \mathrm{pH} 7.4$ ] for $1 \mathrm{~h}$, at $4^{\circ} \mathrm{C}$. Subsequently, the anterior segment of the eye was removed and the retina separated from the pigment epithelium (still maintaining a reference at the dorsal pole) and flattened by making four radial cuts toward the optic nerve head. Routinely, retinas were infiltrated for several hours in $30 \%$ sucrose in $0.1 \mathrm{M} \mathrm{PB}$, frozen in OCT TissueTek, and stored at $-20^{\circ} \mathrm{C}$. On use, retinal samples were brought to room temperature, washed extensively in $0.1 \mathrm{M} \mathrm{PB}$, and left overnight in a solution with $0.5 \%$ Triton $\mathrm{X}-100,10 \%$ rabbit serum, $5 \%$ BSA in PBS, pH 7.4 (Sigma-Aldrich) at $4^{\circ} \mathrm{C}$. Then, retinas were incubated in a 1:500 solution of rabbit anti-GFP-Alexa Fluor 488 (Invitrogen), with $0.1 \%$ Triton $\mathrm{X}-100,1 \%$ rabbit serum, $1 \% \mathrm{BSA}$ in PBS, for $2 \mathrm{~d}$ at $4^{\circ} \mathrm{C}$, to enhance the GFP signal. Retinal specimens were then rinsed three times for $15 \mathrm{~min}$ each time in PBS and incubated in a solution of RNase A (Invitrogen) $\left(1: 1000\right.$ in PBS) at $37^{\circ} \mathrm{C}$ for $1 \mathrm{~h}$. After rinsing in PBS, retinas were stained with $2 \mu \mathrm{M}$ ethidium homodimer- 1 (Invitrogen) for $1 \mathrm{~h}$ at room temperature on a rotary shaker. This allowed fluorescent staining of nuclei necessary to locate the boundaries between retinal layers. Finally, retinas were rinsed extensively in PBS and mounted on glass slides with Vectashield (H1000; Vector Laboratories), "ganglion cells up." Retinal preparations were coverslipped, sealed with nail polish, and inspected with a Zeiss Axioplan fluorescence microscope (Carl Zeiss), using 5 or $10 \times$ objectives. GFP-positive RGCs were localized; when necessary for cell retrieval, low-power images of the whole retinas were taken with a Zeiss Axiocam color camera. Subsequently, well isolated RGCs were scanned with a Leica TCS-NT confocal microscope (Leica Microsystems) equipped with an argon-krypton laser, at resolutions of $1024 \times 1024$ or $512 \times 512$ pixels. Images were obtained using a $25 \times$ PL FLUOTAR 0.75 oil or a $40 \times$ HCX PL APO 1.25 oil objectives. $Z$-stacks were obtained encompassing the optic fiber, ganglion cell (GC), inner plexiform and innermost part of the inner nuclear layers. The distance between adjacent focal planes was set at a constant value $(1013 \mu \mathrm{m})$. Image files were saved in export format and analyzed off-line with MetaMorph (version 5.0r1 MetaMorph; Molecular Devices), to perform three-dimensional reconstructions of single cells and to measure their dendritic tree and body areas. A total number of 50 retinas from different animals was analyzed (Table 1).

Classification of RGCs. RGCs were classified following Sun et al. (2002). Accordingly, the parameters used were (1) the diameter of the dendritic tree; this was obtained measuring with MetaMorph the area of the smallest two-dimensional convex polygon traced along each dendritic tip on a projection of the dendritic arborization when collapsed along the $z$-axis; this measure was repeated three times for each cell; the average was taken as the area of the cell dendritic tree and then used to calculate the diameter, assuming a circular shape of the tree; (2) the diameter of the RGC body, measured after tracing the contour of the projection of the cell body, obtained from optimal, nonsaturated confocal images, usually separate from those used for three-dimensional reconstruction of the cell; (3) the mean stratification depth of the GC dendritic arborization within the inner plexiform layer (IPL), measured on orthogonal projections of the cells obtained from confocal $z$ series, as reported by Badea and Nathans (2004); (4) the shape of the dendritic arbor, according to the description of Sun et al. (2002), as well as following Lin et al. (2004) and Kong et al. (2005); this feature constitutes a blueprint of a cell type and allows the distinction among cells sharing some morphometric parameters. RGC types belonging to the most numerous groups and originating from retinas of different animals were selected for contour tracing and drawn along the whole $z$-stack with Neurolucida software (3.2 version; MicroBrightField). At least four to six cells from each type were traced. Neurolucida data were further analyzed with NeuroExplorer. To evaluate whether modifications in the dendritic complexity occurred as a function of the disease progression, three additional morphological parameters were considered: total dendritic length, total number of nodes, and total dendritic tree area. Data were statistically evaluated with Origin (version 7SR1; OriginLab Corporation). A total of 595 RGCs were classified; of these, 165 were chosen for Neurolucida drawing. They cover 8 different types, of the 17 totally identified by Sun et al. (2002). A summary of the samples examined and of the total number of cells analyzed is reported in Table 1.

Survival in the GCL. Retinal whole mounts obtained as above and counterstained with Ethidium homodimer-1 were used to estimate sur- 
Table 1. RGCs classified and analyzed with Neurolucida at different ages in the rd10/Thy1-GFP-M mutant mouse and in the wt control

\begin{tabular}{|c|c|c|c|c|c|c|c|c|}
\hline \multirow[b]{3}{*}{ RGC type } & \multicolumn{6}{|l|}{ rd10/Thy1-GFP } & \multirow{2}{*}{\multicolumn{2}{|c|}{$\frac{\text { wt/Thy1-GFP }}{8 \text { months }}$}} \\
\hline & \multicolumn{2}{|l|}{3 months } & \multicolumn{2}{|l|}{7 months } & \multicolumn{2}{|l|}{9 months } & & \\
\hline & Classified cells & Analyzed cells & Classified cells & Analyzed cells & Classified cells & Analyzed cells & Classified cells & Analyzed cells \\
\hline A1 & 5 & 5 & 8 & 7 & 5 & 5 & 10 & 5 \\
\hline A2 inner & 9 & 5 & 12 & 5 & 5 & 5 & 18 & 6 \\
\hline A2 outer & 5 & 4 & 4 & 4 & 6 & 5 & 6 & 5 \\
\hline B1 & 12 & 5 & 6 & 5 & 10 & 5 & 8 & 5 \\
\hline B2 & 4 & 0 & 3 & 0 & 6 & 0 & 0 & 0 \\
\hline B3 inner & 23 & 6 & 20 & 5 & 39 & 6 & 13 & 5 \\
\hline B3 outer & 18 & 5 & 13 & 6 & 20 & 5 & 7 & 5 \\
\hline B4 & 8 & 0 & 3 & 0 & 3 & 0 & 3 & 0 \\
\hline $\mathrm{C1}$ & 6 & 0 & 2 & 0 & 6 & 0 & 8 & 0 \\
\hline C 2 inner & 23 & 5 & 14 & 5 & 40 & 5 & 22 & 6 \\
\hline C 2 outer & 19 & 5 & 7 & 5 & 14 & 5 & 11 & 5 \\
\hline C3 & 14 & 0 & 2 & 0 & 7 & 0 & 6 & 0 \\
\hline C4 & 5 & 0 & 0 & 0 & 1 & 0 & 1 & 0 \\
\hline$C 5$ & 2 & 0 & 2 & 0 & 0 & 0 & 2 & 0 \\
\hline C6 & 3 & 0 & 0 & 0 & 1 & 0 & 0 & 0 \\
\hline D1 & 4 & 0 & 2 & 0 & 7 & 0 & 4 & 0 \\
\hline D2 & 7 & 0 & 4 & 0 & 8 & 0 & 6 & 0 \\
\hline Unclassified ON & 6 & 0 & 6 & 0 & 7 & 0 & 1 & 0 \\
\hline Unclassified OFF & 2 & 0 & 1 & 0 & 0 & 0 & 0 & 0 \\
\hline Total cells/age & 175 & 40 & 109 & 42 & 185 & 41 & 126 & 42 \\
\hline Total retinas/age & 15 & & 12 & & 12 & & 11 & \\
\hline TOTAL RGCs classified & 595 & & & & & & & \\
\hline TOTAL RGCs analyzed & 165 & & & & & & & \\
\hline
\end{tabular}

vival of cells in the GC layer (GCL) of rd10/Thyl-GFP-M and wt/Thy1GFP-M aged 9 months. Four retinas from different animals were used for rd10/Thy1-GFP-M and three for control mice. Confocal microscopy was used to obtain serial optical sections at $1013 \mu \mathrm{m}$ intervals encompassing the thickness of the entire GCL, using a $40 \times$ objective as above. Sampling areas were 16 fields $(250 \times 250 \mu \mathrm{m})$ per retina, regularly spaced along the dorsal-ventral and nasal-temporal retinal meridians. Counts of cells were performed on extended-focus images of the GCL, covering an average thickness of $20 \mu \mathrm{m}$ on the $z$ plane. Endothelial and perivascular cells were excluded from the counts on the basis of their characteristic shape and high intensity of staining. Total numbers of cells per retina were obtained multiplying average cellular densities by corresponding retinal areas. These were measured on low magnification images obtained at the Zeiss light microscope with a Zeiss Axiocam camera. Statistical analysis (one-way ANOVA) on cell counts was performed with Origin 7.0.

Additional counts were performed on retinas from rd10/Thy1GFP-M, rd10, and C57BL/6J animals aged 9 months $(n=3$ retinas for each strain). These were incubated as explained above but with goat polyclonal antibodies against Brn3b (Millipore), a transcription factor selectively expressed in a large fraction of adult RGCs. Images of the GCL were obtained at the confocal microscope at peripheral and central retinal locations, using a $40 \times$ oil-immersion objective. Cellular densities were estimated for each retinal sample and compared statistically by one-way ANOVA.

Anterograde axonal transport. This was studied in RGCs by injection of fluorescent B subunit of cholera toxin into the eyes of seven rd10, three rd10/Thy1-GFP-M, and three C57BL6J wt mice aged 9 months. Animals were anesthetized as above; $0.5 \mu \mathrm{l}$ of biotinylated cholera toxin B fragment $(10 \mathrm{mg} / \mathrm{ml})$ (Sigma-Aldrich) was injected into the vitreous of the left eye; $0.5 \mu \mathrm{l}$ of FITC-cholera toxin $(1 \mathrm{mg} / \mathrm{ml}$; Alexa Fluor 488 conjugate; Invitrogen) was injected into the right eye. Injections were done under a high-power dissecting microscope using a glass micropipette with a tip diameter of $\sim 0.5 \mu \mathrm{m}$ (Clarke Electromedical Instruments), driven by a hydraulic micromanipulator. Twenty-four hours after the injection, mice were perfused transcardially with $4 \%$ PFA in $0.1 \mathrm{M} \mathrm{PB}, \mathrm{pH}$ 7.4. The brains were dissected and postfixed in $4 \%$ PFA for $2 \mathrm{~h}$. After rinsing in buffer, brains were infiltrated overnight in 30\% sucrose and frozen in dry ice. Coronal brain sections ( $40 \mu \mathrm{m}$ thick) were obtained with a freezing sliding microtome. Selected sections containing the lateral geniculate nucleus (LGN) or the superior colliculus (SC) were incubated overnight in Cy3-conjugated avidin (1:500; Invitrogen), rinsed in PBS three times for 15 min each time, mounted in glycerol, and visualized at the confocal microscope. Acquisitions were done using $5 \times(\mathrm{N}-$ PLAN 0.12) and $10 \times($ N-PLAN 0.25) dry objectives. Brightness and contrast of images were adjusted with Adobe Photoshop CS.

\section{Results}

There are 12-17 types of RGCs in the retina of the mouse: as in all mammals, these neurons can be distinguished on the basis of their morphological and functional features (Sun et al., 2002; Carcieri et al., 2003; Badea and Nathans, 2004; Kong et al., 2005; Coombs et al., 2006). To characterize the effects of retinal degeneration on individual RGCs, we took advantage of the M-line of Thy1-GFP transgenic mice, in which the GFP transgene, controlled by thy- 1 cassette (Caroni, 1997), is expressed in a small number of RGCs, so that these neurons are entirely labeled (axon, soma, and dendrites) but rarely overlap (Feng et al., 2000). As previously reported, GFP labeling of RGCs is semirandom, in the sense that some cell types are encountered more frequently, irrespectively to their density in the retina.

We crossed homozygous Thy-1/GFP-M transgenics with rd10 mutant mice, a model of autosomal recessive human RP. rd10/ Thy1-GFP-M mice displayed the same temporal and spatial pattern of photoreceptor degeneration described for the parent rd10 strain (Chang wet al., 2002; Gargini et al., 2007). Secondary changes detected in bipolar and horizontal cells also adhered strictly to what found in the original rd10 mutant. Photoreceptor degeneration and second-order neuron alterations are summarized in supplemental Figure 1 (available at www.jneurosci.org as supplemental material). 

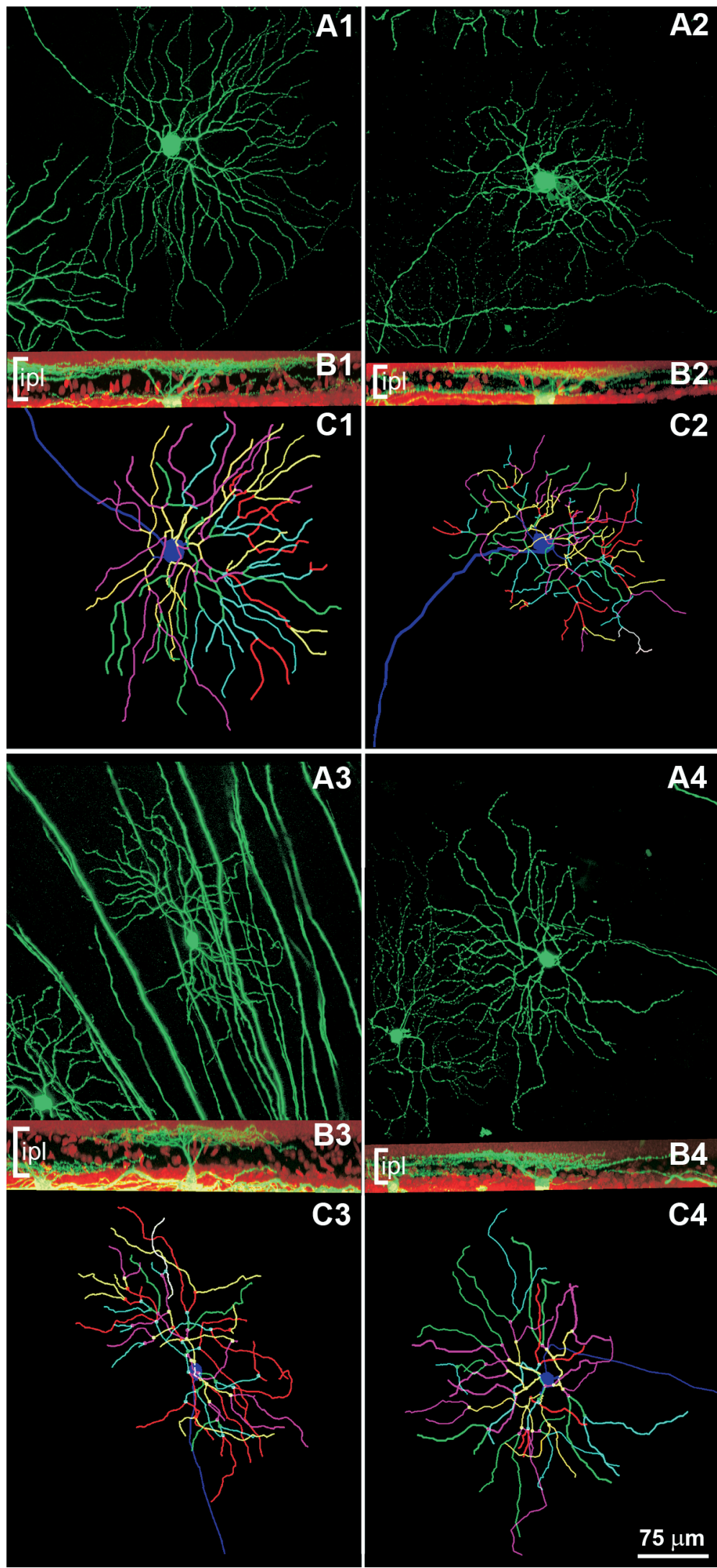

Figure 1. Four types of RGCS of the rd10/Thy1-GFP-M retina with dendritic stratification in the outer one-half of the IPL (functionally, OFF-type RGCS). Age, 9 months. In all RGC illustrations, the top panel ( $\boldsymbol{A}$ ) represents a whole-mount view of an individual cell projected in a single plane; the central panel $(\boldsymbol{B})$ is the orthogonal view on the same cells obtained by computer rotation, also showing ethidium nuclear staining (red signal); the bottom panel $(\boldsymbol{C})$ represents the Neurolucida drawing of each cells. Different colors code for different branching order of the dendrites: blue, first order; yellow, second; orange, third; pink, fourth; green, fifth; cyan, sixth; red, seventh; red, brown, eighth; purple, ninth; white, tenth. A1-C1, GCs belonging to the A2
As shown previously (Lin et al., 2004), different types of RGCs are encountered at various rates in the Thyl-GFP-M line, with no single retina exhibiting every existing type of RGC labeled. In the rd10/ Thy1-GFP-M strain, the number of GFPpositive RGCs is lower that in the parent strain ( $\sim 30$ cells/retina). Although the origin of such variability is not clear, it appears that only the analysis of numerous retinal samples can give an account of most of the existing types of RGCs (Table 1).

\section{RGC morphology}

The analysis of 469 RGCs from rd10/ Thyl-GFP-M mutant mice belonging to the three age groups selected $(3,7$, and 9 months of age) did not reveal obvious morphological abnormalities in any of them. Each cell could be appropriately assigned to a formerly described type as deduced by morphology, depth of stratification, and dendritic and cell body area. In total, we studied the morphology of eight types of RGCs (A1, A2 inner and outer, B1, B3 inner and outer, and C2 inner and outer). These include four types of cells ramified in the outer part of the IPL (functionally defined as "OFF" varieties) (Fig. 1) and four types ramified in the inner part of the IPL ("ON" varieties) (Fig. 2). Large-, medium-, and small-sized RGCs are comprised in the groups studied and some of these have homologs in other mammalian retinas. Their distinctive features are summarized in supplemental Tables 1 and 2 (available at www.jneurosci.org as supplemental material), using the system of names provided by Sun et al. (2002).

A set of morphological aberrations have previously been described for bipolar and horizontal cells of the rd10 mutant (Gargini et al., 2007; Barhoum et al., 2008), as well as for RGCs of rodents with other retinal and systemic diseases (i.e., glaucoma and diabetes). These include the following: retraction and atrophy of dendrites ("pruning"), cell body shrinkage or hypertrophy, and loss of laminar organization and degeneration (Jakobs et al., 2005; Gastinger et al., 2008; Kern and Barber, 2008). None of these was detected in any of the cells observed. Aberrant elongation of dendrites, axonal ectopic branching ("sprouting"), also observed in RGCs and other neurons of various disease models (Cheng et al., 1998; Phokeo et al., 2002;

\section{$\leftarrow$}

outer type. $\mathbf{A 2}-\mathbf{C} 2, \mathrm{GCS}$ belonging to the $\mathrm{B} 1$ type. $\mathbf{A} \mathbf{3}-\mathbf{C} \mathbf{3}, \mathrm{GCS}$ classified as B3 outer type. A4 -C4, Example of ganglion cells belonging to the $\mathrm{C} 2$ outer type. 
Pignatelli et al., 2004) were not detectable in the RGCs of the strain under study. All the cells examined were undistinguishable from those of mice without photoreceptor degeneration, as judged from comparisons with 126 RGCs labeled in adult Thy1GFP-M mice that did not carry the $\mathrm{rd} 10$ mutation.

From all the RGCs labeled in rd10/ Thy1-GFP-M mice, we selected a pool of 123 neurons belonging to the eight types listed above for a computational analysis of the dendritic morphology and complexity as a function of age. Parameters for complexity assessment were the area of the dendritic tree, the total dendritic length, and the total number of nodes. For each cell type, at each age, parameters were obtained from Neurolucida tracings and compared with those of corresponding RGCs $(n=42)$ from adult, Thyl-GFP-M mouse retinas. All three indicators of dendritic tree complexity are highly sensitive to alterations in the architecture of arborizations: either sprouting or pruning is immediately reflected into changes in the parameters measured, commonly used to assess neuronal responses to injury, disease, or environmental conditions (i.e., Alpár et al., 2003). Fixing confidence interval at level of 0.01 , statistical analysis by oneway ANOVA revealed that there were no significant differences in morphometric parameters among mutants of various age groups and between mutant and wt $(p$ value for each analysis is reported in supplemental Table 3, available at www. jneurosci.org as supplemental material). Measures remained identical to corresponding parameters of RGCs of the same types from adult retinas from Thy1GFP-M mice. In turn, these conformed entirely to measurements from mouse RGCs of identical types available from the literature (Sun et al., 2002; Badea and Nathans, 2004; Coombs et al., 2006) (Figs. $3,4)$. Correlated parameters, such as dendritic density, defined as the ratio of the number of nodes to the dendritic tree area, were also maintained in each cell. For additional examples of RGCs classified for this study, see supplemental Figures 2-4 (available at www.jneurosci.org as supplemental material).

We conclude that RGCs in the rd10 mutant mouse retain their characteristic morphology and fine dendritic geometry well beyond the complete death of photoreceptors and despite major alterations of other retinal cell classes (Gargini et al., 2007).

We identified numerous RGCs with dendrites branching in both the inner and
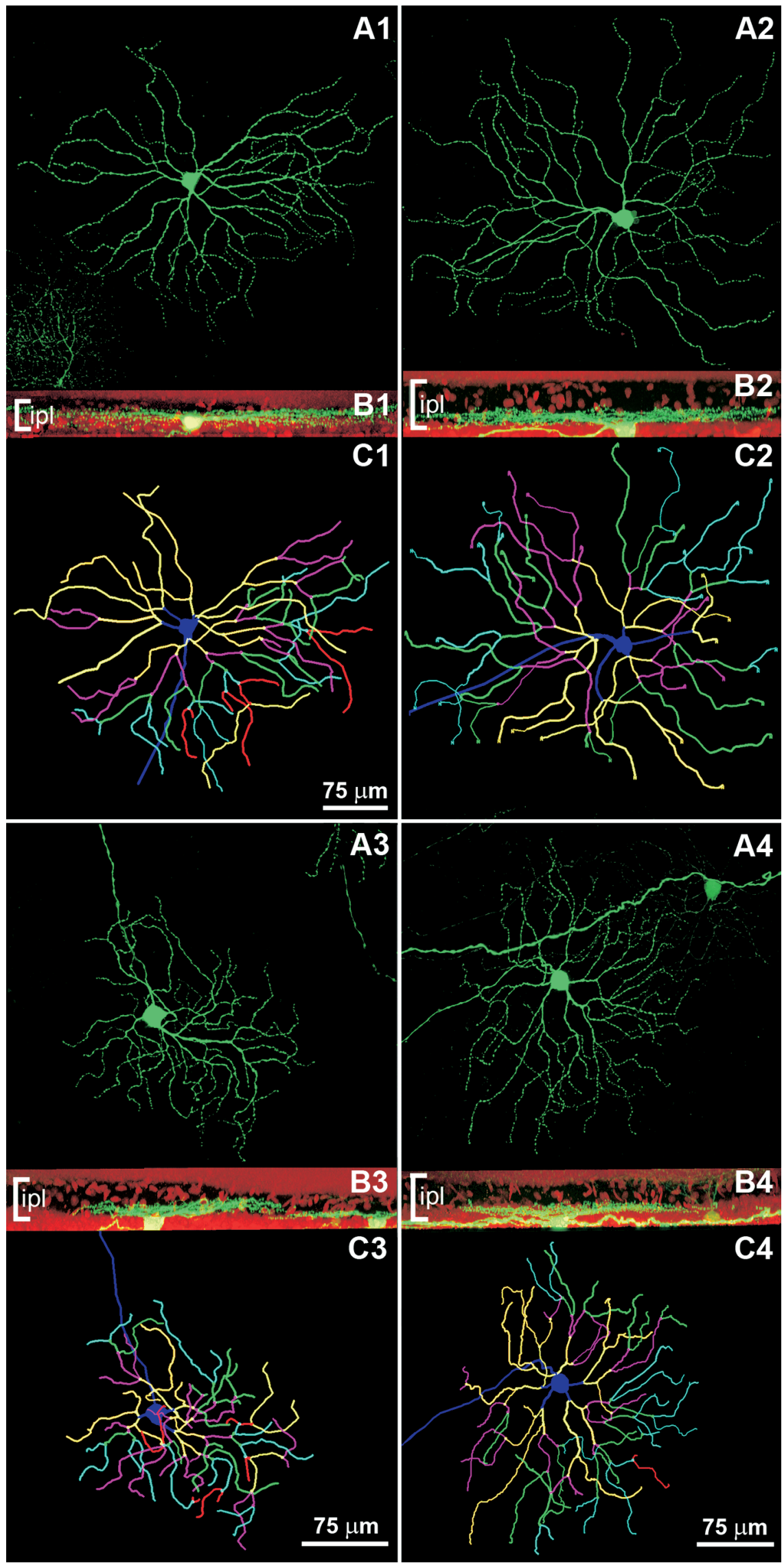

Figure 2. Four types of RGCS of the rd10/Thy1-GFP-M retina with dendritic stratification in the inner one-half of the IPL (functionally, ON-type RGCS). Age, 9 months. A1-C1, Example of A1 type GC. A2-C2, Example of A2 inner GC. A3-C3, Example of B3 inner GC. A4 - C 4 , Example of $C 2$ inner GC. 


\section{a}

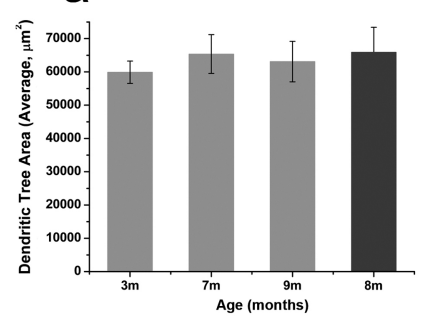

b

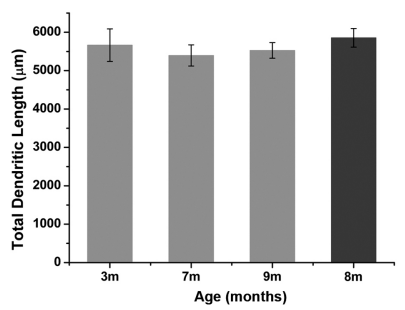

C

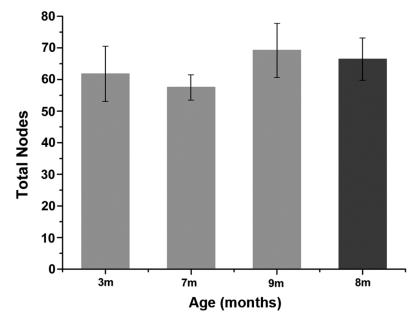

B1
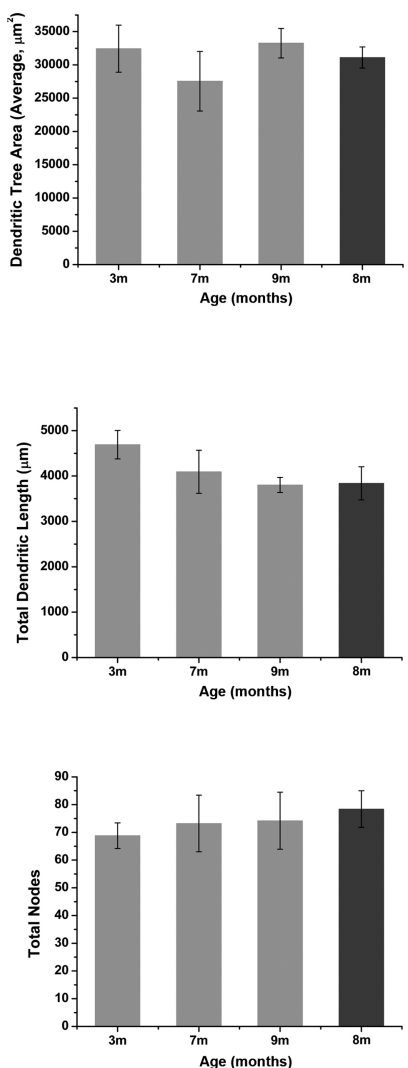

B3outer
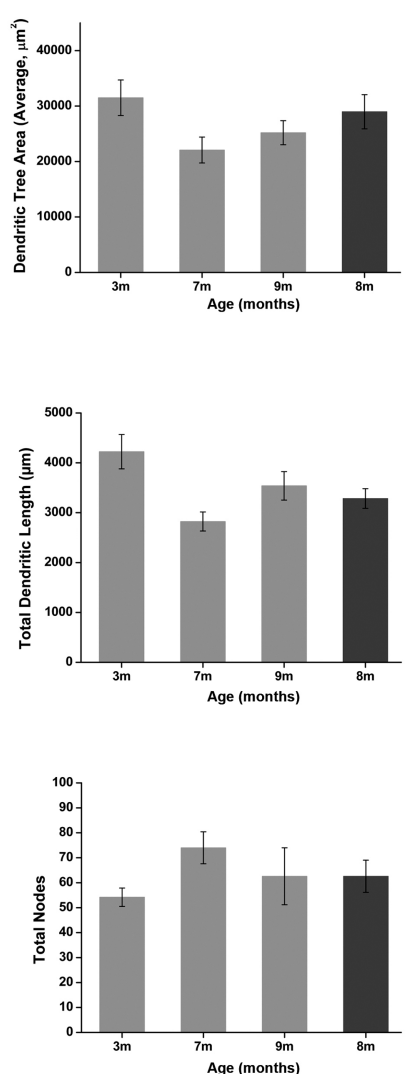

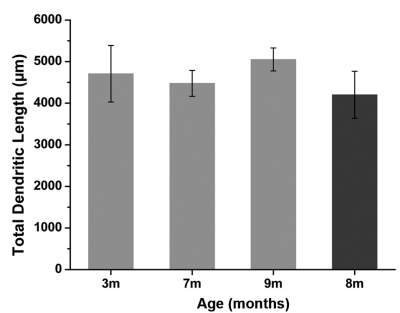

C2outer
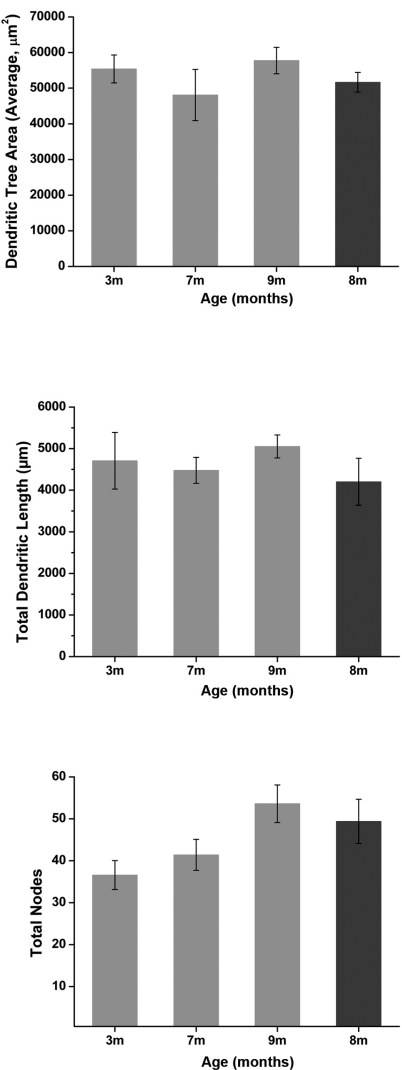

Figure 3. Indicators of dendritic tree complexity for four types of RGCs with dendrites in the outer one-half of the IPL (OFF RGCs). Parameters from the rd10 mutant (gray columns) are compared with corresponding values obtained from wt mice aged 8-9 months (dark columns). Diagrams in the three rows illustrate dendritic tree area, dendritic tree length, and total number of nodes for the three age groups examined (3,7, and 9 months). Each column represents average data from four to six cells \pm SEM. Statistical analysis with one-way ANOVA shows no significant differences between RGCs of rd10/Thy1-GFP-M and control mice ( $p>0.01)$.

outer halves of the IPL; these are the well known bistratified RGCs $(n=32)$. They were assigned to either the D1 or D2 types (Table 1) following Sun et al. (2002). We could not assess the dendritic tree complexity because they show enormous heterogeneity in the size of both arborizations and in their branching depth in the IPL. However, no major deviations from known morphometric and morphological features were evident in these cells in the rd10/Thy1-GFP-M mutant retinas (supplemental Fig. 3, available at www.jneurosci.org as supplemental material).

Displaced RGCs were encountered in almost all the rd10/ Thy1-GFP-M and control retinas examined, particularly in the nasal quadrant. For these rare neurons, Sun et al. (2002) did not provide a classification. Our sample included members of the monostratified, displaced (ON or OFF) types, and, more rarely, exemplars of the bistratified type (ON-OFF). Their morphology appeared undistinguishable from their counterparts observed in Thy1-GFP-M retinas (supplemental Fig. 4, available at www. jneurosci.org as supplemental material). Finally, several cells defined by Sun et al. (2002) as "unclassified" were also encountered in Thy1-GFP-M and retinal degeneration mice of various ages (Table 1; supplemental Fig. 4, available at www.jneurosci.org as supplemental material). None of these cells showed signs of morphological abnormality.

\section{RGC survival}

We counted the nuclei of all the neurons in the GCL of animals aged 9 months, with the rationale that the oldest age would in- crease the chance of detecting secondary degeneration of RGCs. The number of cells in the GCL of rd10 mice (both $\mathrm{rd10}$ and rd10/Thy1-GFP-M mutants) did not change in time and was statistically identical to that of wt, control animals (Fig. 5A-C). This finding is quite consistent, because we sampled a large fraction of the retinal surface (i.e., a total of $4 \mathrm{~mm}^{2} /$ retina or $\sim 28 \%$ of the total retinal area) and we took into account all the eccentricities. Because using this method we could not distinguish between amacrine and GCs, we stained rd10, rd10/Thy1-GFP-M, and wt retinas, aged 9 months, with antibodies against Brn3b, a transcription factor expressed in the majority of adult RGCs (de Melo et al., 2003). Counting of Brn3b-positive profiles in retinal whole mounts returned statistically identical densities $(\alpha=0.01)$ of RGCs in mutant and wt retinas (Fig. 5D-G).

We concluded that survival and detailed morphology are excellent in RGCs of both rd10 and rd10/Thy1-GFP-M mutants.

\section{RGC axonal transport and central projections}

Axons of RGCs fasciculate along the optic nerves and tracts to reach higher visual centers. Almost all RGC axons project to the SC and $\sim 30 \%$ send collaterals that reach the dorsal LGN. Central projections can be visualized using B subunit of cholera toxin, a commonly used anterograde neuronal tracer that is actively taken up and transported by neurons. After injecting in the eyes of rd10, rd10/Thy1-GFP-M, and control mice, aged 9 months, fluorescent or biotinylated cholera toxin, we recovered a normal pattern of labeling in both the LGN (Fig. 6) and the SC (supplemental Fig. 

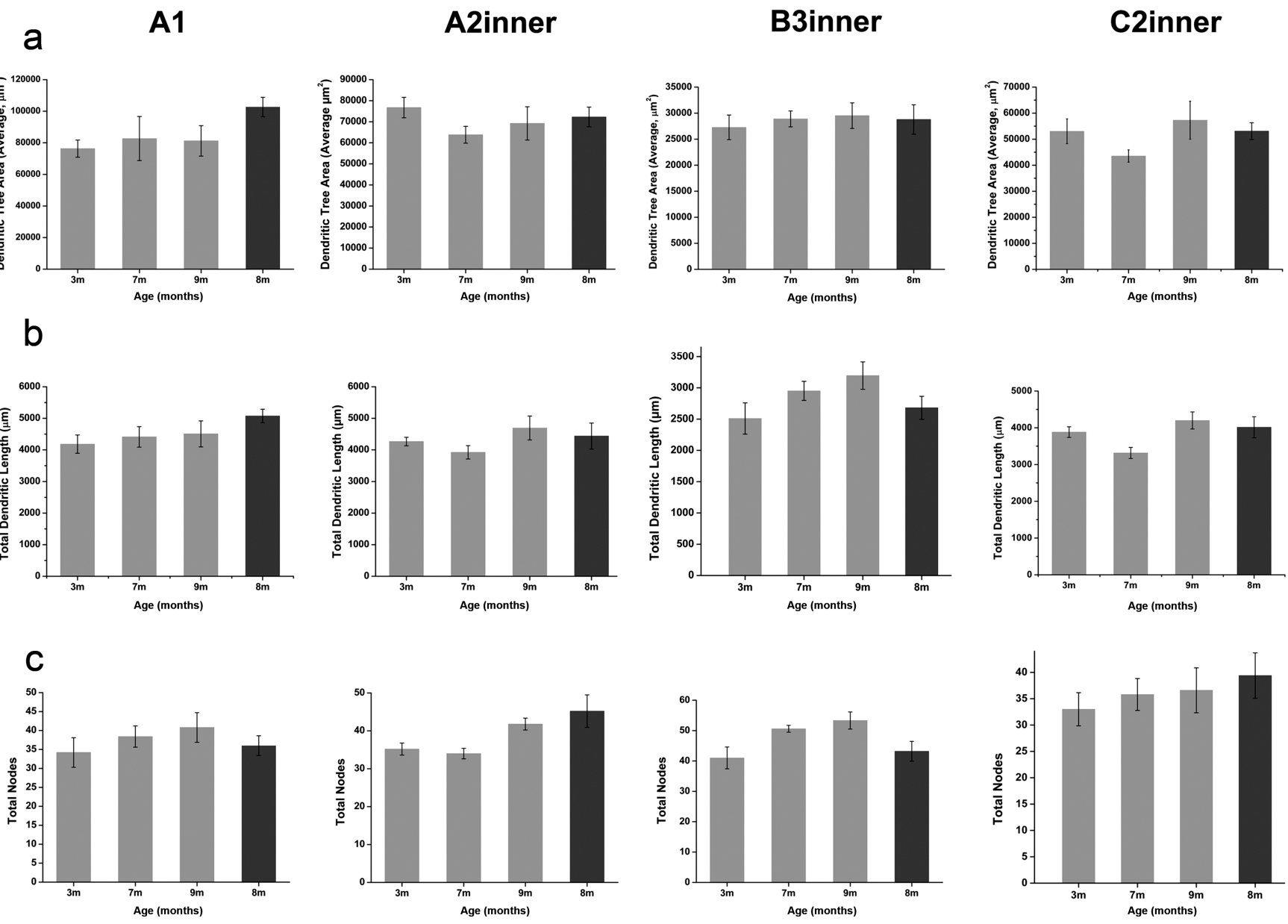

Figure 4. Indicators of dendritic tree complexity for four types of RGCs with dendrites in the inner one-half of the IPL (ON RGCS). Parameters from the rd10/Thy1-GFP-M mutant (gray columns) are compared with corresponding values obtained from wt mice aged 8 months (dark columns). Diagrams in the three rows illustrate dendritic tree area, dendritic tree length, and total number of nodes for the three age groups examined (3, 7, and 9 months). Each column represents average data from four to six cells \pm SEM. Statistical analysis with one-way ANOVA shows no significant differences between RGCs of rd10/Thy1-GFP-M mice and control mice ( $p>0.01$ ).

5, available at www.jneurosci.org as supplemental material), thus obtaining evidence of preserved anterograde axonal transport from RGCs to central visual targets. The pattern of retinofugal projections of RGCs in rd10 mutant mice appeared also undistinguishable from that of wt mice (Fig. 6; supplemental Fig. 5, available at www.jneurosci.org as supplemental material).

\section{Discussion}

By crossing a transgenic expressing GFP in RGCs with a phosphodiesterase mutant with a typical rod-cone degeneration, we could demonstrate remarkable preservation of fine dendritic architecture, complete survival, retention of anterograde axonal transport, and maintenance of a normal projection pattern in RGCs of a mouse model of typical RP. The individual cell analysis includes both ON and OFF functional varieties of RGCs, as well as some of the best characterized RGCs types in mammals (i.e., $\alpha$ RGCs). These data strongly suggest overall RGC viability in this model of typical, autosomal-recessive, RP.

Many signs of pathology are evident in RGCs of animal models of various retinal diseases, typically glaucoma and diabetes. These can be divided into regressive changes (i.e., reduction in size of cell body and dendritic arborization), loss of fine dendritic branches (pruning) and, eventually, cell death; and more plastic alterations, comprising abnormal lamination and dendritic and axonal elongation (sprouting). We found no signs of such pathological changes in the RGCs of rd10/Thy1-GFP-M mice after analyzing almost 600 cells of various types. Yet in the same retinas, we confirmed regressive remodeling of bipolar and horizontal cells, already reported for this mutant by us and by others (Gargini et al., 2007; Barhoum et al., 2008). Moreover, morphometric evaluation of eight of all the types of RGCs described for the mouse retina confirmed preservation of fine dendritic architecture in these neurons even at 9 months of age, well beyond the complete loss of all photoreceptors.

Obviously, GFP-positive ganglion cells in the Thy1-GFP-M mouse were identical with RGCs of the mouse retina described by others using different methods, including the use of an alkaline phosphatase reporter in retinal neurons (Badea and Nathans, 2004), Lucifer yellow injections (Sun et al., 2002; Coombs et al., 2006), DiI diolistic labeling, and GFP transgenic expression. The preservation of fundamental morphological features detected in RGCs of the rd10/Thy1-GFP-M mutant was confirmed also when the same neurons were separated into discrete types using a different taxonomy from that introduced by Sun et al. (2002). For instance, most RGCs belonging to the A1 inner and A2 inner types of the present study fall into cluster no. 8 of Kong et al. (2005). "A type" RGCs of the rd10/Thy1-GFP-M retina falling in 

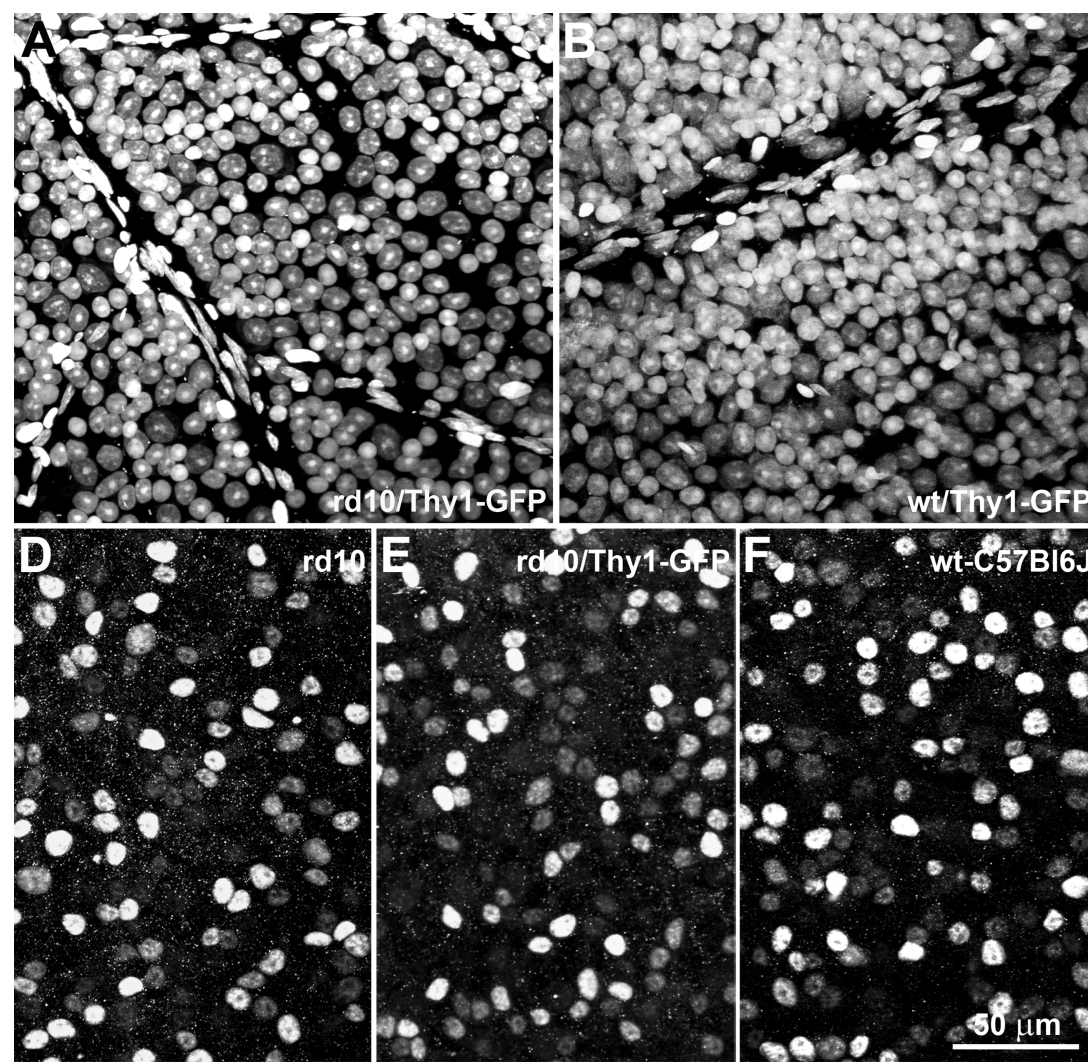

C

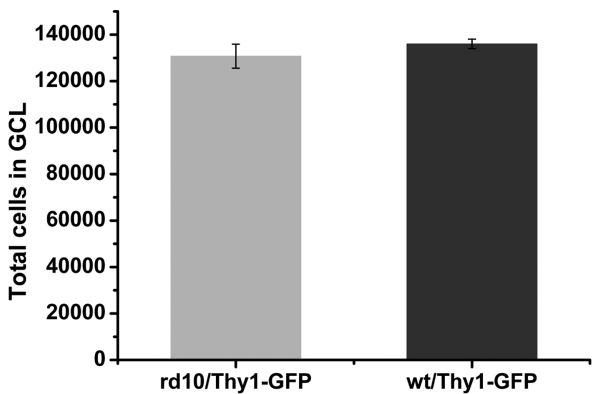

G

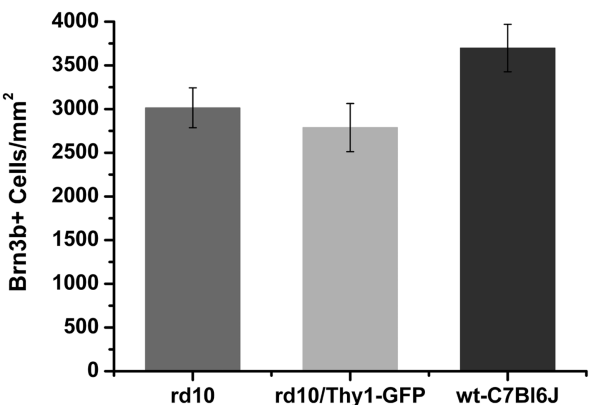

Figure 5. Survival of cells in the GCL of rd10/Thy1-GFP-M mice at 9 months. $\boldsymbol{A}, \boldsymbol{B}$, Images of the GCL in wt $(\boldsymbol{A})$ and mutant mice $(\boldsymbol{B})$. Ethidium nuclear staining and projection on a single plane of the entire GCL thickness. Elongated, bright nuclei belong to blood vessel cells. C,Cellular counting demonstrates that there are no differences in the wt (left, $136,000 \pm 2040$ cells) and mutant retinas (right, 130,750 \pm 5100 ). The two populations are statistically identical ( $p>0.01)$. D $-\boldsymbol{F}$, Brn3b immunostaining of cells in the GCL. This transcription factor is localized in the cell nuclei. $\mathbf{G}$, Similar densities of Brn3b-positive cells were found in the three strains of mice at 9 months of age. The three populations are statistically identical ( $p>0.01)$.

cluster no. 8 at 3 months of age also maintain the parameters typical of that cluster at 7 and 9 months, confirming retention of their fundamental morphological properties. Thus, morphological preservation of RGCs in the rd10/Thy1-GFP-M mutant, which exactly match RGC types of "normal," wild-type mice, is confirmed also when unsupervised classification criteria are used.

We and others have shown that, in mutants with inherited photoreceptor degenerations, inner retinal cells undergo various degrees of remodeling. This complex process occurs at different rates and with variable aggressiveness partly as a function of the mutation causing the disease and the time of onset of the primary death of rods. Stereotyped aspects of remodeling involve Müller glial reactivity and abnormalities in rod bipolar and horizontal cells, the neurons directly postsynaptic to degenerating rods. Dendritic atrophy, complex phenotypic deconstruction, and secondary death of these neurons have been shown in various animal models and appear as a consistent finding (Marc et al., 2003).

Dendritic atrophy and secondary death are typical reaction to synaptic deafferentation described previously in the CNS, for instance among LGN neurons when the optic nerve is severed (Somogyi et al., 1987) or in deafferented neurons of the nucleus laminaris maintained in vitro (Sorensen and Rubel, 2006). One would have expected that, ultimately, the consequences of progressive transynaptic degeneration initiated by the primary loss of photoreceptors would need to be propagated to the RGCs. This does not appear to be the case, at least based on the finding on rd10 mutants described here. Dendritic atrophy, degeneration, and loss of molecular markers, reported for outer retinal cells (supplemental Fig. 1, available at www.jneurosci.org as supplemental material), are not detectable at all in RGCs of the rd10/ Thyl-GFP-M mutant mouse, in the 3-9 month time window. Virtually no functional photoreceptors are left in the retina at that time, and most bipolar cells (both rod and cone bipolars) have remodeled extensively. Glial reactivity and atrophy of blood vessels are a part of the common response to damage or remodeling (Otani et al., 2004). Yet RGCs appear stable in fine morphology and number. Systemic conditions, including diabetes and hypertension, have been reported to affect the morphology of RGCs, exhibiting irregularly swollen and beaded dendrites, reduction in arborization size and branching frequency (MeyerRüsenberg et al., 2007). Ultimately, these cells undergo apoptotic death. If this is the eventual fate of RGCs in the rd10/Thy1GFP-M mutant as well, then those changes occur at a very slow rate, totally separated in time from photoreceptor death.

Other kinds of evidence suggest that retention of function in RGCs might also be a common aspect of inherited photoreceptor degeneration. Morphological studies aimed at detecting responsiveness to glutamate in RGCs of various RP mutants have indicated that these neurons are extremely active through ionotropic glutamatergic receptors even when their input neurons (cone bipolar cells) cannot generate glutamatergic signals (Marc et al., 2007). Indeed multielectrode recordings from the retina of $\mathrm{rd} 1$ mutant mice, a widely used model of early-onset recessive RP, demonstrate increased excitability in RGCs, persisting well after the disappearance of any functioning photoreceptors (Stasheff, 2008). Very recently, single-cell recordings from different types of ON and OFF RGCs demonstrated retention of highly distinc- 
tive membrane and firing properties, overall suggestive of inherent stability of these neurons during retinal degeneration (Margolis et al., 2008). A detailed study of RGCs morphology in the rd1 mutant is in progress in our laboratory; whatever the findings might be, it can be concluded already that activity itself does not seem necessary to RGC survival: In nob2 mutant mice, a case in which a mutation in a calcium channel of photoreceptors causes impaired transmission of signals from the outer to the inner retina, but without physical degeneration of the photoreceptors, RGCs appear to retain their basic center-surround organization (Chang et al., 2006). It could be the case that mutations occurring in the outer retina have limited effects on RGCs.

Several aspects could contribute to the better preservation of RGCs than of rod bipolar and horizontal cells inherited photoreceptor degeneration. First of all, both rod bipolar and horizontal cells lose all of their synaptic inputs on photoreceptor demise. Neither one of these second-order neurons is directly connected to RGCs, which receive their input from cone bipolar and amacrine cells. Because remodeling of cone bipolar cells is relatively slower (Strettoi et al., 2002; Cuenca et al., 2004), one should then expect a proportionately longer time before the effects of deafferentation have an impact onto RGCs.

Intraretinal circuitry generating aberrant synaptic input and causing persistent excitation of RGCs might also contribute to their viability. Although the source of retinal generated activity is still a matter of debate, it might be speculated that activity itself could contribute to viability of RGCs, because it is well known that silenced neurons in vitro and in vivo suffer from progressive atrophy and death (Ramakers and Boer, 1991; Catsicas et al., 1992). Melanopsin RGCs, intrinsically responsive to light, are known to survive and to retain spiking activity in degenerated retinas (Semo et al., 2003; Zhu et al., 2007); it is possible that melanopsin-initiated electrical signals invade other retinal neurons as well, although the pathway used for such a propagation needs to be clarified.

RGC survival could also be supported by their central targets as well, by means of synaptic and trophic interactions. Finally, astrocytes of the retina and optic nerve could play a supportive role in the long run: these cells are known to release trophic factors and might respond to retinal degeneration by exerting a protective action, similarly to what has been described in various examples of CNS injury (So-
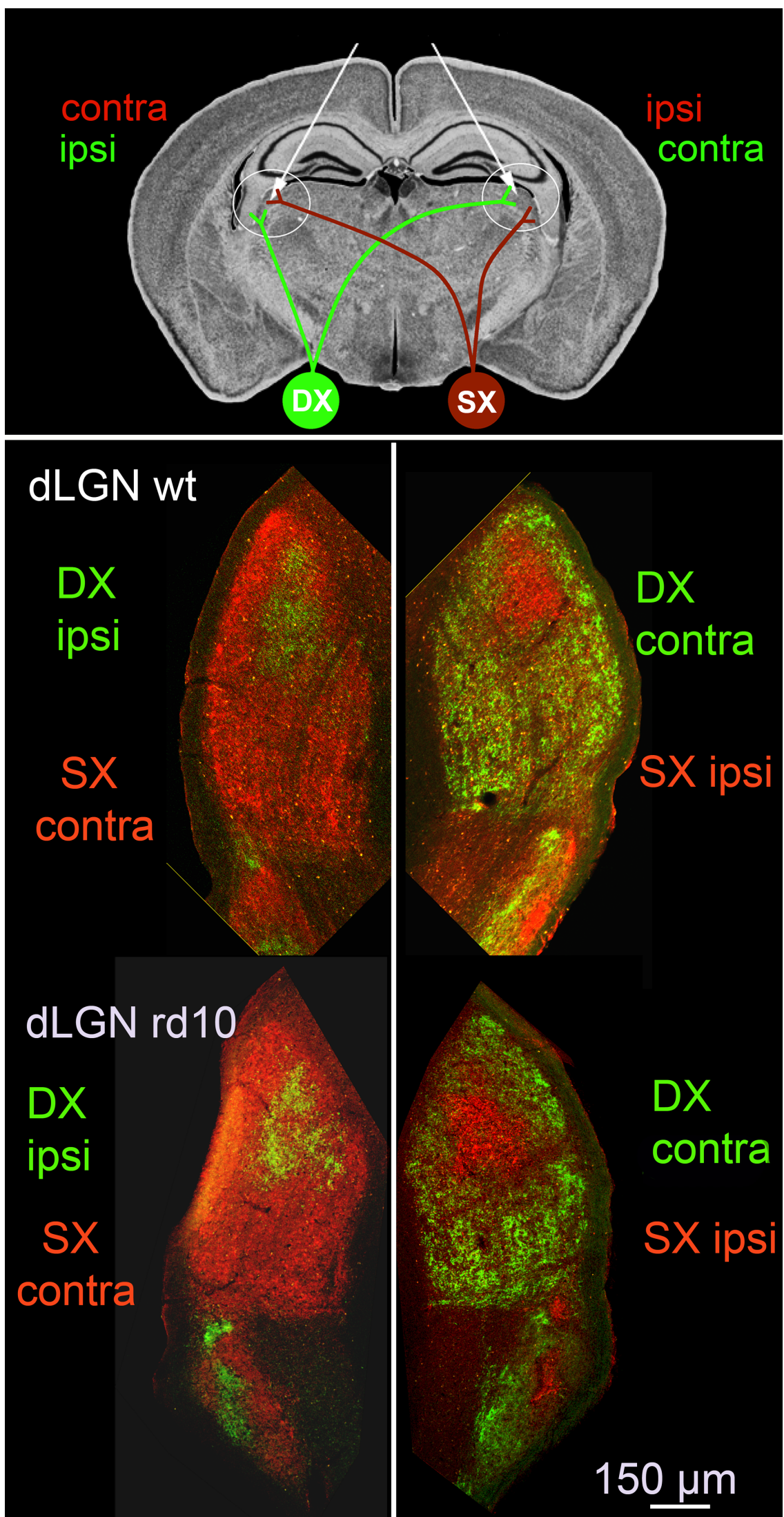

Figure 6. Anterograde axonal transport of RGCs to central projection areas. $A$, Schematic diagram showing the ipsilateral and contralateral projections of optic nerve axons to the dorsal part of the lateral geniculate nucleus (dLGN). B, C, Coronal sections of the dLGN from wt ( $\boldsymbol{B}$ ) and rd10 ( $C$ mutant mice aged 9 months, after injections of cholera toxin conjugated to different fluorophores in the two eyes. Each pair of images shows complementary red/green fields, comprising a large projection from the contralateral eye and a small field, receiving the ipsilateral projection. ipsi, Ipsilateral; contra, contralateral; DX, right side; SX, left side. 
froniew, 2005). Additional trophic support could be exerted also by exogenous devices including electronic prostheses implanted to restore vision (DeMarco et al., 2007).

This is one of the few single-cell studies illustrating the effects of inherited photoreceptor degeneration on RGCs of various types, in a time window encompassing both early and late stages after rod and cone death. Whatever the mechanism supporting RGC viability might be, the findings reported here have consequences for the treatment of the family of disorders collectively known as RP. RGCs are the only retinofugal neurons and are also the cells stimulated directly by epiretinal prostheses and indirectly by certain types of subretinal electronic implants (Winter et al., 2007). Their long-term viability in an animal model that closely resembles recessive RP suggests that RGCs may be a better target of activation than the bipolar cells for restoring vision in humans with similar phenotypes. Although there are certain advantages to prosthetic or molecular stimulation of bipolar cells, their greater propensity to degenerate may make the ganglion cells a more desirable target in attempts to restore vision after photoreceptor degeneration.

\section{References}

Alpár A, Palm K, Schierwagen A, Arendt T, Gärtner U (2003) Expression of constitutively active $\mathrm{p} 21 \mathrm{H}$-rasval 12 in postmitotic pyramidal neurons results in increased dendritic size and complexity. J Comp Neurol 467:119-133.

Badea TC, Nathans J (2004) Quantitative analysis of neuronal morphologies in the mouse retina visualized by using a genetically directed reporter. J Comp Neurol 480:331-351.

Barhoum R, Martínez-Navarrete G, Corrochano S, Germain F, FernandezSanchez L, de la Rosa EJ, de la Villa P, Cuenca N (2008) Functional and structural modifications during retinal degeneration in the rd10 mouse. Neuroscience 155:698-713.

Bi A, Cui J, Ma YP, Olshevskaya E, Pu M, Dizhoor AM, Pan ZH (2006) Ectopic expression of a microbial-type rhodopsin restores visual responses in mice with photoreceptor degeneration. Neuron 50:23-33.

Carcieri SM, Jacobs AL, Nirenberg S (2003) Classification of retinal ganglion cells: a statistical approach. J Neurophysiol 90:1704-1713.

Caroni P (1997) Overexpression of growth-associated proteins in the neurons of adult transgenic mice. J Neurosci Methods 71:3-9.

Catsicas M, Péquignot Y, Clarke PG (1992) Rapid onset of neuronal death induced by blockade of either axoplasmic transport or action potentials in afferent fibers during brain development. J Neurosci 12:4642-4650.

Chang B, Hawes NL, Hurd RE, Davisson MT, Nusinowitz S, Heckenlively JR (2002) Retinal degeneration mutants in the mouse. Vision Res 42:517-525.

Chang B, Heckenlively JR, Bayley PR, Brecha NC, Davisson MT, Hawes NL, Hirano AA, Hurd RE, Ikeda A, Johnson BA, McCall MA, Morgans CW, Nusinowitz S, Peachey NS, Rice DS, Vessey KA, Gregg RG (2006) The nob2 mouse, a null mutation in Cacnalf: anatomical and functional abnormalities in the outer retina and their consequences on ganglion cell visual responses. Vis Neurosci 23:11-24.

Chang B, Hawes NL, Pardue MT, German AM, Hurd RE, Davisson MT, Nusinowitz S, Rengarajan K, Boyd AP, Sidney SS, Phillips MJ, Stewart RE, Chaudhury R, Nickerson JM, Heckenlively JR, Boatright JH (2007) Two mouse retinal degenerations caused by missense mutations in the betasubunit of rod cGMP phosphodiesterase gene. Vision Res 47:624-633.

Cheng HW, Tong J, McNeill TH (1998) Lesion-induced axon sprouting in the deafferented striatum of adult rat. Neurosci Lett 242:69-72.

Coombs J, van der List D, Wang GY, Chalupa LM (2006) Morphological properties of mouse retinal ganglion cells. Neuroscience 140:123-136.

Cuenca N, Pinilla I, Sauvé Y, Lu B, Wang S, Lund RD (2004) Regressive and reactive changes in the connectivity patterns of rod and cone pathways of P23H transgenic rat retina. Neuroscience 127:301-317.

DeMarco PJ Jr, Yarbrough GL, Yee CW, McLean GY, Sagdullaev BT, Ball SL, McCall MA (2007) Stimulation via a subretinally placed prosthetic elicits central activity and induces a trophic effect on visual responses. Invest Ophthalmol Vis Sci 48:916-926.

de Melo J, Qiu X, Du G, Cristante L, Eisenstat DD (2003) Dlx1, Dlx2, Pax6,
Brn3b, and Chx10 homeobox gene expression defines the retinal ganglion and inner nuclear layers of the developing and adult mouse retina. J Comp Neurol 461:187-204.

Eisenfeld AJ, LaVail MM, LaVail JH (1984) Assessment of possible transneuronal changes in the retina of rats with inherited retinal dystrophy: cell size, number, synapses, and axonal transport by retinal ganglion cells. J Comp Neurol 223:22-34.

Feng G, Mellor RH, Bernstein M, Keller-Peck C, Nguyen QT, Wallace M, Nerbonne JM, Lichtman JW, Sanes JR (2000) Imaging neuronal subsets in transgenic mice expressing multiple spectral variants of GFP. Neuron 28:41-51.

Gargini C, Terzibasi E, Mazzoni F, Strettoi E (2007) Retinal organization in the retinal degeneration $10(\operatorname{rd} 10)$ mutant mouse: a morphological and ERG study. J Comp Neurol 500:222-238.

Gastinger MJ, Kunselman AR, Conboy EE, Bronson SK, Barber AJ (2008) Dendrite remodeling and other abnormalities in the retinal ganglion cells of Ins2 Akita diabetic mice. Invest Ophthalmol Vis Sci 49:2635-2642.

Grafstein B, Murray M, Ingoglia NA (1972) Protein synthesis and axonal transport in retinal ganglion cells of mice lacking visual receptors. Brain Res 44:37-48.

Jakobs TC, Libby RT, Ben Y, John SW, Masland RH (2005) Retinal ganglion cell degeneration is topological but not cell type specific in DBA/2J mice. J Cell Biol 171:313-325.

Jensen RJ, Rizzo JF 3rd (2006) Thresholds for activation of rabbit retinal ganglion cells with a subretinal electrode. Exp Eye Res 83:367-373.

Jensen RJ, Ziv OR, Rizzo JF (2005) Responses of rabbit retinal ganglion cells to electrical stimulation with an epiretinal electrode. J Neural Eng 2:S16-S21.

Jones BW, Marc RE (2005) Retinal remodeling during retinal degeneration. Exp Eye Res 81:123-137.

Jones BW, Watt CB, Frederick JM, Baehr W, Chen CK, Levine EM, Milam AH, Lavail MM, Marc RE (2003) Retinal remodeling triggered by photoreceptor degenerations. J Comp Neurol 464:1-16.

Kern TS, Barber AJ (2008) Retinal ganglion cells in diabetes. J Physiol 586:4401-4408.

Kong JH, Fish DR, Rockhill RL, Masland RH (2005) Diversity of ganglion cells in the mouse retina: unsupervised morphological classification and its limits. J Comp Neurol 489:293-310.

Lagali PS, Balya D, Awatramani GB, Münch TA, Kim DS, Busskamp V, Cepko CL, Roska B (2008) Light-activated channels targeted to ON bipolar cells restore visual function in retinal degeneration. Nat Neurosci 11:667-675.

Lin B, Wang SW, Masland RH (2004) Retinal ganglion cell type, size, and spacing can be specified independent of homotypic dendritic contacts. Neuron 43:475-485.

Lin B, Koizumi A, Tanaka N, Panda S, Masland RH (2008) Restoration of visual function in retinal degeneration mice by ectopic expression of melanopsin. Proc Natl Acad Sci U S A 105:16009-16014.

Loewenstein JI, Montezuma SR, Rizzo JF 3rd (2004) Outer retinal degeneration: an electronic retinal prosthesis as a treatment strategy. Arch Ophthalmol 122:587-596.

Marc RE, Jones BW, Watt CB, Strettoi E (2003) Neural remodeling in retinal degeneration. Prog Retin Eye Res 22:607-655.

Marc RE, Jones BW, Anderson JR, Kinard K, Marshak DW, Wilson JH, Wensel T, Lucas RJ (2007) Neural reprogramming in retinal degeneration. Invest Ophthalmol Vis Sci 48:3364-3371.

Margolis DJ, Newkirk G, Euler T, Detwiler PB (2008) Functional stability of retinal ganglion cells after degeneration-induced changes in synaptic input. J Neurosci 28:6526-6536.

McLaughlin ME, Sandberg MA, Berson EL, Dryja TP (1993) Recessive mutations in the gene encoding the beta-subunit of rod phosphodiesterase in patients with retinitis pigmentosa. Nat Genet 4:130-134.

Meyer-Rüsenberg B, Pavlidis M, Stupp T, Thanos S (2007) Pathological changes in human retinal ganglion cells associated with diabetic and hypertensive retinopathy. Graefes Arch Clin Exp Ophthalmol 245:1009-1018.

Milam AH, Li ZY, Fariss RN (1998) Histopathology of the human retina in retinitis pigmentosa. Prog Retin Eye Res 17:175-205.

Otani A, Dorrell MI, Kinder K, Moreno SK, Nusinowitz S, Banin E, Heckenlively J, Friedlander M (2004) Rescue of retinal degeneration by intravitreally injected adult bone marrow-derived lineage-negative hematopoietic stem cells. J Clin Invest 114:765-774. 
Phokeo V, Kwiecien JM, Ball AK (2002) Characterization of the optic nerve and retinal ganglion cell layer in the dysmyelinated adult Long-Evans Shaker rat: evidence for axonal sprouting. J Comp Neurol 451:213-224.

Pignatelli V, Cepko CL, Strettoi E (2004) Inner retinal abnormalities in a mouse model of Leber's congenital amaurosis. J Comp Neurol 469:351-359.

Ramakers GJ, Boer GJ (1991) Chronic suppression of bioelectric activity and cell survival in primary cultures of rat cerebral cortex: biochemical observations. Eur J Neurosci 3:154-161.

Rizzo JF 3rd, Wyatt J, Loewenstein J, Kelly S, Shire D (2003) Methods and perceptual thresholds for short-term electrical stimulation of human retina with microelectrode arrays. Invest Ophthalmol Vis Sci 44:5355-5361.

Santos A, Humayun MS, de Juan E Jr, Greenburg RJ, Marsh MJ, Klock IB, Milam AH (1997) Preservation of the inner retina in retinitis pigmentosa. A morphometric analysis. Arch Ophthalmol 115:511-515.

Semo M, Peirson S, Lupi D, Lucas RJ, Jeffery G, Foster RG (2003) Melanopsin retinal ganglion cells and the maintenance of circadian and pupillary responses to light in aged rodless/coneless ( $\mathrm{rd} / \mathrm{rd} \mathrm{cl}$ ) mice. Eur J Neurosci 17:1793-1801.

Sofroniew MV (2005) Reactive astrocytes in neural repair and protection. Neuroscientist 11:400-407.

Somogyi J, Eysel U, Hamori J (1987) A quantitative study of morphological reorganization following chronic optic deafferentation in the adult cat dorsal lateral geniculate nucleus. J Comp Neurol 255:341-350.

Sorensen SA, Rubel EW (2006) The level and integrity of synaptic input regulates dendrite structure. J Neurosci 26:1539-1550.
Stasheff SF (2008) Emergence of sustained spontaneous hyperactivity and temporary preservation of OFF responses in ganglion cells of the retinal degeneration (rd1) mouse. J Neurophysiol 99:1408-1421.

Stone JL, Barlow WE, Humayun MS, de Juan E Jr, Milam AH (1992) Morphometric analysis of macular photoreceptors and ganglion cells in retinas with retinitis pigmentosa. Arch Ophthalmol 110:1634-1639.

Strettoi E, Pignatelli V (2000) Modifications of retinal neurons in a mouse model of retinitis pigmentosa. Proc Natl Acad Sci U S A 97:11020-11025.

Strettoi E, Porciatti V, Falsini B, Pignatelli V, Rossi C (2002) Morphological and functional abnormalities in the inner retina of the $\mathrm{rd} / \mathrm{rd}$ mouse. J Neurosci 22:5492-5504.

Strettoi E, Pignatelli V, Rossi C, Porciatti V, Falsini B (2003) Remodeling of second-order neurons in the retina of $\mathrm{rd} / \mathrm{rd}$ mutant mice. Vision Res 43:867-877.

Sun W, Li N, He S (2002) Large-scale morphological survey of mouse retinal ganglion cells. J Comp Neurol 451:115-126.

Walia S, Fishman GA (2008) Retinal nerve fiber layer analysis in RP patients using Fourier-domain OCT. Invest Ophthalmol Vis Sci 49:3525-3528.

Winter JO, Cogan SF, Rizzo JF 3rd (2007) Retinal prostheses: current challenges and future outlook. J Biomater Sci Polym Ed 18:1031-1055.

Zhu Y, Tu DC, Denner D, Shane T, Fitzgerald CM, Van Gelder RN (2007) Melanopsin-dependent persistence and photopotentiation of murine pupillary light responses. Invest Ophthalmol Vis Sci 48:1268-1275.

Zrenner E (2002) Will retinal implants restore vision? Science 295:10221025. 